\title{
Long-Term (7 Years) Follow-Up of Roux-en-Y Gastric Bypass on Obese Adolescent Patients ( $<18$ Years)
}

\author{
Ramon Vilallonga Jacques Himpens Simon van de Vrande \\ Division of Bariatric Surgery, AZ St-Blasius, Dendermonde, Belgium
}

\section{Key Words}

Adolescent $<18$ years · Roux-en-Y gastric bypass · Obesity · Laparoscopy · Retrospective study $\cdot$ Contraception

\begin{abstract}
Background: Few data are available about obesity surgery in adolescent patients. Objective: To assess long-term outcomes after laparoscopic Roux-en-Y gastric bypass (LRYGB) in patients <18 years. Setting: University Hospital, Europe. Methods: A retrospective study of prospectively collected data of patients $<18$ years (childhood group; $\mathrm{ChG})(\mathrm{n}=28)$ treated by LRYGB of which 19 were available for follow-up between 2.4 and 10.2 years (mean 7.2 years). This group of patients was matched with an adult control group (AdG) of randomly chosen patients with similar characteristics who underwent LRYGB during the same period. The extensive survey included a telephonic questionnaire. Results: 19 (12 females) of the 28 patients (67.9\%) were available for follow-up. Preoperatively, 3 had type 2 diabetes mellitus (T2DM), 1 arterial hypertension, 5 dyslipidemia and 1 sleep apnea. In the ChG, average BMI after 7 years dropped from $38.9 \mathrm{~kg} / \mathrm{m}^{2}$ preoperatively to $27.5 \mathrm{~kg} / \mathrm{m}^{2}$. In the $A d G$, average BMI decreased from 39.4 to $27.1 \mathrm{~kg} / \mathrm{m}^{2}$ in the same time period (nonsignificant between groups). One patient in the ChG needed a reoperation (internal hernia) versus 3 patients in the AdG (1 leak, 2 obstructions). All patients resolved their initial comorbidities. Two of 12 female patients in the ChG became pregnant 6 and 8 years after surgery, respectively, despite seemingly adequate oral contraception. Compliance with postoperative guidelines was good in 16/19 patients in ChG and in 14/18 patients in the AdG. Overall degree of satisfaction was high: 8.2/10 (SD 1.2, range $6-10$ ) in the ChG and 8.9/10 (SD 1.7, range 5-10) in the AdG. Conclusion: LRYGB seems to be safe, provide good weight loss, and cure comorbidities in an adolescent population. Satisfaction degree is high. Inadvertent pregnancy despite conventional contraception is a possible issue.


Vilallonga et al.: Long-Term (7 Years) Follow-Up of Roux-en-Y Gastric Bypass on Obese Adolescent Patients ( $<18$ Years)

\section{Introduction}

Obesity is a common disease that affects all age groups [1]. In 1998, the World Health Organization warned that obesity had reached the rank of a pandemic and that its prevalence was increasing alarmingly, both in adult and child populations [2]. In the USA, 32\% of children between 10 and 17 years are overweight and 16\% are obese. In addition, the incidence of obesity has tripled over the last 30 years [1-3]. The obesity problem seems to be self-perpetuating, considering that a significant percentage of adolescents suffering from morbid obesity persist in being obese in adulthood [4, 5-7].

Surgical treatment is the only long-term effective treatment against obesity [8,9]. As in adults, medical treatment is only moderately effective in adolescents and has a limited impact on weight loss [10]. Data suggest that adolescents with morbid obesity, aged between 15 and 17 years, have elevated levels of C-reactive protein. This blood marker for inflammation that in adults is considered an early warning sign for future heart disease is elevated in obese adolescents compared to healthy-weight adolescents [11]. Additionally, young obese patients have an increased number of psychological problems [12,13].

More often than not, after medical treatment, including a dietary control and increase of physical activity, surgical management of adolescent morbid obesity is needed [14]. Some selected centers have shown promising results with different surgical techniques [15-17]. In our department, the laparoscopic Roux-en-Y gastric bypass (LRYGB) was elected to treat morbidly obese adolescents. This article provides our long-term results of LRYGB in adolescents and analyze the overall process in terms of early outcomes, complications, compliance, satisfaction and follow-up results.

\section{Material and Methods}

From May, 2003 to December, 2008, 28 carefully selected adolescent patients underwent a LRYGB procedure for morbid obesity. Patients were referred to our department after multidisciplinary treatment, by psychologists, nutritionists, endocrinologists and pediatricians. All patients previously underwent medical, dietary and multimodal treatment in the De Haan Sea Preventorium which is a national health center offering multidisciplinary inpatient continuous care inclu ding strict dietary supervision and physical activity programs (fig. 1). Once the decision was made to undergo surgery according to our protocol, standard laparoscopic gastric bypass was performed. A systematic review of our prospective database was performed. For each patient, relevant data, such as age at the time of surgery, initial BMI in $\mathrm{kg} / \mathrm{m}^{2}$ ) and comorbidities, were evaluated. Additionally, follow-up data were collected, including complications, resolution of comorbidities, years after surgery with nadir weight and follow-up details such as dietary habits. Type 2 diabetes mellitus (T2DM) was diagnosed when a fasting plasma glucose test showed values $>126 \mathrm{mg} / \mathrm{dl}$ and glycated hemoglobin $\left(\mathrm{HBA}_{1 \mathrm{C}}\right)$ was $>6.2 \%$. Dyslipidemia was defined as low-density lipoprotein (LDL) $>130 \mathrm{mg} / \mathrm{dl}$ or when treatment with a statine drug was necessary. Sleep apnea was diagnosed in patients treated with a continuous positive airway pressure machine. Finally high blood pressure was considered when patients were treated with at least two antihypertensive drugs. A specific assessment was done in view of this study by a telephone questionnaire that included questions related to the number of check-up visits each year, vitamins supplementation (including calcium, zinc and multivitamin intake per day) contraceptive methods among females, and degree of satisfaction with the surgical procedure and the overall process. The degree of satisfaction was ranked from 0 to 10,0 being absolutely unsatisfied and 10 absolutely satisfied. The questionnaire was proposed via telephone to all patients reached. Efforts to reach the patients included several attempts to contact the patient by the use of our institutional database or, if not successful, by getting in touch with the general practitioner. Once the childhood group (ChG) was considered complete, a comparison adult group (AdG) was obtained by randomly choosing adult obese patients who had undergone LRYGB during the same period of time and who were matched for gender and BMI. The patients in the AdG were investigated using the same methodology, including the telephonic questionnaire and visit in the outpatient clinic for all patients. All patient from AdG were seen in the outpatient clinic. 
Fig. 1. Algorithm showing the protocol used in the department to establish adolescent candidates to surgery. ${ }^{*}$ Comorbidity included: diabetes mellitus, sleep apnea (apnea-hypopnea index > 15), pseudotumor cerebri, nonalcoholic steatosis hepatitis (NASH). Note: dyslipidemia and cardiovascular conditions are not included. ${ }^{* *}$ De Haan sea preventorium is a national health center offering multidisciplinary inpatient continuous care including strict dietary supervision and physical activities program.
Vilallonga et al.: Long-Term (7 Years) Follow-Up of Roux-en-Y Gastric Bypass on Obese Adolescent Patients ( $<18$ Years)

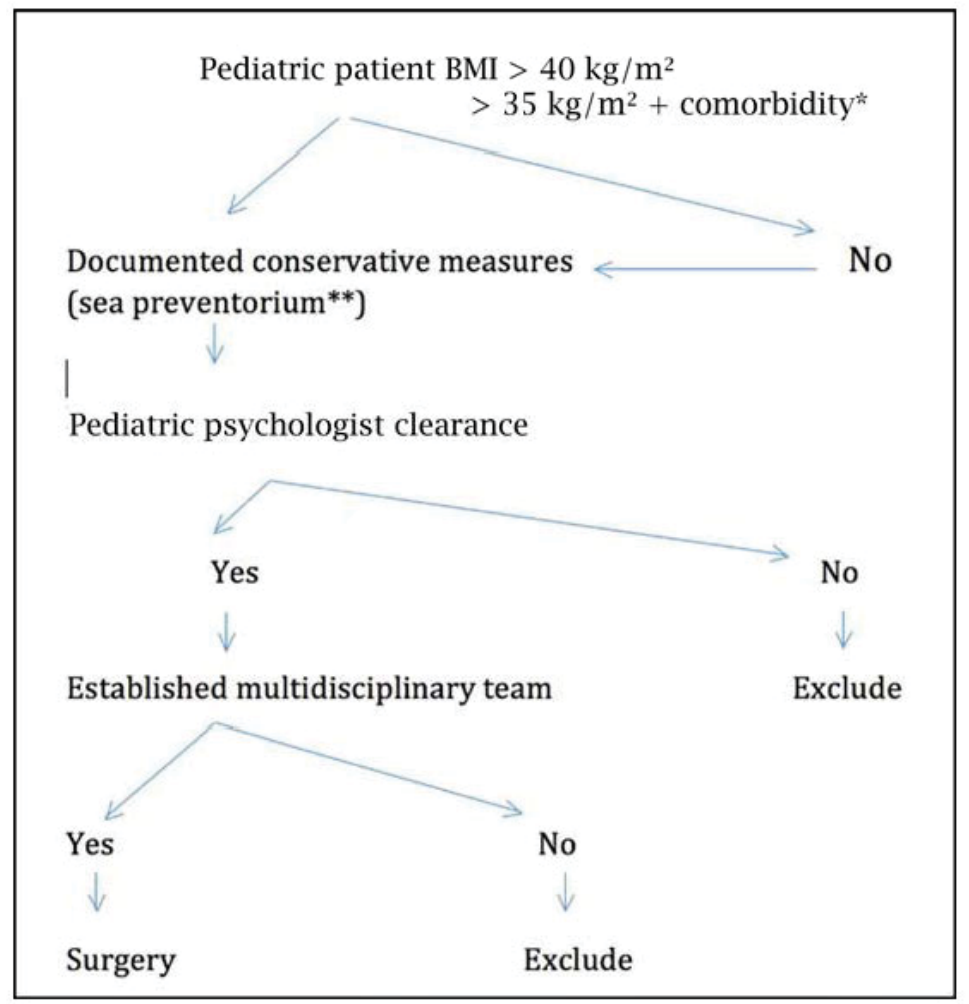

Statistical analyses were carried out using SPSS 1.5 software (SPSS, Chicago, IL, USA). The two-tailed t-test for non-paired variables was used for evaluating postoperative time and the continuous variables BMI. Significance was assumed for $\mathrm{p}<0.05$.

\section{Results}

Of the 28 adolescent patients of the cohort, 19 were available for full evaluation consisting of office visit and questionnaire response (68\%). The outcomes of the ChG were compared to the data of the AdG, and there were no significant differences between the two groups in terms of gender, BMI, and mean follow-up time (table 1).

There were 15 females in the ChG and 14 in the AdG. Mean age of the adolescents at the time of the procedure was 15.5 years (range 13-17 years). Mean age of the AdG was 39.4 years (range 35-45 years). Mean BMI for the ChG at the time of the procedure was 38.9 $\mathrm{kg} / \mathrm{m}^{2}$ (range $35-44 \mathrm{~kg} / \mathrm{m}^{2}$ ). A similar BMI was recorded for the AdG $\left(39.4 \mathrm{~kg} / \mathrm{m}^{2}\right.$ ) (range $35-45 \mathrm{~kg} / \mathrm{m}^{2}$ ). At the time of the procedure, 3 adolescents had unsuspected T2DM, 5 suffered from dyslipidemia, 1 from sleep apnea, and 1 from high blood pressure. In the AdG, 4 patients had T2DM, 4 high blood pressure, 6 dyslipidemia, and 1 sleep apnea.

In the ChG, 12 of the 19 patients had an uneventful postoperative course, and 1 required a laparoscopic reoperation for an internal hernia. In the AdG, 12 of the 18 patients also did not suffer any complications but 3 needed a reoperation for obstruction $(n=2)$ or leak $(n=$ 1). The mean follow-up time was 7.2 years for the ChG and 7.7 years for the AdG. The nadir weight was achieved after 3.7 years in the ChG and after 2.3 years in the AdG ( $p=0.021)$. BMI at follow-up was $27.5 \mathrm{~kg} / \mathrm{m}^{2}$ (range: $21.8-35.2 \mathrm{~kg} / \mathrm{m}^{2}$ ) in the $\mathrm{ChG}$ and $23.4 \mathrm{~kg} / \mathrm{m}^{2}(16.2-28.1$ $\mathrm{kg} / \mathrm{m}^{2}$ ) in the AdG (BMI loss was not significant between the two groups, $\mathrm{p}=0.235$ ). All 
Vilallonga et al.: Long-Term (7 Years) Follow-Up of Roux-en-Y Gastric Bypass on Obese Adolescent Patients ( $<18$ Years)

Table 1. General data of the patients who underwent bariatric surgery

\begin{tabular}{lll}
\hline & $\begin{array}{l}\text { Childhood group } \\
(\mathrm{n}=19)\end{array}$ & $\begin{array}{l}\text { Adult group } \\
(\mathrm{n}=18)\end{array}$ \\
\hline Gender (M/F) & $4 / 15$ & $4 / 14$ \\
\hline Mean age (min-max), years & $15.5(13-17)$ & $37.9(23-61)$ \\
\hline Mean BMI at surgery (min-max), $\mathrm{kg} / \mathrm{m}^{2}$ & $38.9(35-44)$ & $39.4(35-45)$ \\
\hline Comorbidities present & & \\
T2DM & 3 & 4 \\
Arterial hypertension & 1 & 4 \\
Dyslipemia & 5 & 6 \\
Sleep apnea & 1 & 1 \\
\hline Complications & & \\
$\quad$ None & 12 & 12 \\
Leak & 0 & 0 \\
Gastric ulcer & 2 & 0 \\
Bleeding & 0 & 0 \\
Internal hernia & 1 & 2 \\
Obstruction & 0 & 3 \\
Other (minor) & 4 &
\end{tabular}

patients from both groups recovered from their initial comorbidities. Analyzing the longterm follow-up of the patients, 13 patients from the AdG mentioned to adhere to a strict follow-up regime with blood analyses (2-4 analyses per year) and adequate vitamins intake (compliance 72\%). Conversely, 16 adolescents were controlled but 3 of them claimed not having any type of follow-up despite advice, and denied vitamins intake. In the AdG, 5 patients had blood work on a regular basis, and 6 denied vitamin intake. The overall compliance rate in the AdG was $72 \%$. A specific question concerning fertility, pregnancy, and contraceptive methods showed that 2 out of 12 female patients (17\%) of the ChG who were taking classical contraceptive measures became pregnant 6 or 8 years after the surgery despite use of an oral contraceptive. Conversely, 6 out of 9 patients (66\%) who did want children became pregnant and delivered without problems.

Overall, the degree of satisfaction after the procedure was high (8.2 in the ChG and 8.9 in the AdG). Most of the patients of both groups ( $82 \%$ in the $\mathrm{ChG}$ and $78 \%$ in the AdG) would be willing to undergo a similar procedure to treat their obesity (table 2).

\section{Discussion}

Morbidly obese patients have an increased risk for metabolic complications. This is also valid for obese adolescents $[11,18]$. Remarkably, starting at the age of 3 years, two-thirds of morbidly obese children have two or more cardiovascular risk factors [11]. Additionally, a substantial number of these children have significant comorbidities that are typically observed in obese adults [11]. One study that included individuals between 5 and 17 years showed that $70 \%$ of obese children and adolescents presented with at least one cardiovascular risk factor, and in $39 \%$ of obese children at least two cardiovascular risk factors could be demonstrated 
Vilallonga et al.: Long-Term (7 Years) Follow-Up of Roux-en-Y Gastric Bypass on Obese Adolescent Patients ( $<18$ Years)

Table 2. Follow-up data and degree of satisfaction of the patients

\begin{tabular}{|c|c|c|}
\hline & $\begin{array}{l}\text { Childhood group } \\
(\mathrm{n}=19)\end{array}$ & $\begin{array}{l}\text { Adult group } \\
(\mathrm{n}=18)\end{array}$ \\
\hline Analyzed period & $5 / 2003-10 / 2010$ & $11 / 2003-12 / 2008$ \\
\hline Patients available for follow-up (\%) & $19 / 28(68 \%)$ & $18 / 18$ \\
\hline Gender (M/F) & $4 / 15$ & $4 / 14$ \\
\hline Mean follow-up time (min-max), years & $7.2(2.4-10.2)$ & $7.7(4.7-9.5)$ \\
\hline Mean BMI at follow-up (min-max), $\mathrm{kg} / \mathrm{m}^{2}$ & $27.5(21.8-35.2)$ & $27.1(21.4-36.9)$ \\
\hline \multicolumn{3}{|l|}{ Comorbidities resolution, $\%$} \\
\hline T2DM & 100 & 100 \\
\hline Arterial hypertension & 100 & 100 \\
\hline Dyslipemia & 100 & 100 \\
\hline Use of CPAP & 100 & 100 \\
\hline Mean age of minimal weight (min-max), years & $19.2(14.0-24.0)$ & $40.1(23.0-65.0)$ \\
\hline Mean years after surgery with minimal weight (min-max), years & $3.7(0.8-7.0)$ & $2.3(0.8-6.0)$ \\
\hline Mean minimal BMI (min-max), $\mathrm{kg} / \mathrm{m}^{2}$ & $23.7(19.4-30.5)$ & $23.4(16.2-28.1)$ \\
\hline Minimal weight, kg & $67.4(54.0-88.0)$ & $62.9(42.0-85.0)$ \\
\hline \multicolumn{3}{|l|}{ Follow-up, number of patients } \\
\hline No blood analysis & 3 & 5 \\
\hline Blood analysis 1-2/year & 0 & 0 \\
\hline Blood analysis 2-4/year & 16 & 13 \\
\hline Vitamins intake (yes/no) & $16 / 3$ & $12 / 6$ \\
\hline Oral contraceptive pills & & \\
\hline Spiral & 1 & 0 \\
\hline Pills & 9 & 2 \\
\hline Slow release hormones & 1 & 0 \\
\hline Hormone diaphragm & 1 & 1 \\
\hline None & 4 & 0 \\
\hline Pregnancy with ОСР (yes/no) & $2 / 12$ & $1 / 3$ \\
\hline Children (yes/no) & $6 / 9$ & \\
\hline \multicolumn{3}{|l|}{ Degree of satisfaction } \\
\hline Related to the procedure $(0-10)$ (mean, SD, min-max) & $8.2,1.6,2-10$ & $7.9,2.7,0-10$ \\
\hline Related to the overall process $(0-10)$ (mean, SD, min-max) & $8.9,1.2,6-10$ & $8.0,1.7,5-10$ \\
\hline Would you do it again? $(0-10)$ (mean, SD, min-max) & $8.2,2.1,2-10$ & $7.7,2.8,0-10$ \\
\hline
\end{tabular}

[19]. When analyzing the psychological effects of obesity in adolescents, depression, low selfesteem, poor interaction with peers, anxiety, suicide, and severe psychosocial problems are strikingly more frequently observed in this group than in the non-obese population $[18,19]$.

As for adults, childhood obesity treatment should include measures to promote changes in lifestyle, eating habits, self-esteem, and family communication [20]. However, a significant 
Vilallonga et al.: Long-Term (7 Years) Follow-Up of Roux-en-Y Gastric Bypass on Obese Adolescent Patients $(<18$ Years $)$

percentage of patients will not be able to reverse their obesity and may consider surgical treatment [21]. Changes induced by bariatric surgery in adolescents will mitigate the deleterious effects of morbid obesity, but this should not disturb the brittle overall equilibrium of the adolescent $[18,22]$.

Several surgical approaches to treat adolescent morbidly obese patients have been described. They include the biliopancreatic diversion (BPD) with its inherent risks related to malabsorption and technical difficulty of the operation [23-25]. Nowadays, BPD has lost popularity to the benefit of other techniques that are seemingly simpler and appear to carry a lower incidence of complications and mortality. One of the most popular 'simpler' procedures is the laparoscopic adjustable gastric band (LAGB). The LAGB is an attractive treatment mode because of its excellent results, its alleged reversibility, and its absence of nutritional deficits [26]. LAGB has been shown to be more effective compared to medical treatment in these patients [26]. Some studies show acceptable weight loss, but weight loss ranges between $15 \%$ and $87 \%$ of excess weight $[15,27-29]$. LAGB has been shown to improve the quality of life [30, 31]. Further studies with more than 200 teenagers confirmed the weight loss figures for a period of 6 months to 7 years, with no deaths and a complication rate of $6-10 \%[32,33]$. However, a higher rate of reoperation for failure was reported in adolescents undergoing LAGB compared to those undergoing gastric bypass [34-36]. The high rate of reoperation and band removal (nearly 50\%) was previously found in our study on adult patients over a 12-year period [37]. This situation may be a significant issue for adolescents with a life expectancy of several decades. Additionally, there appears to be an increased rate of gastroesophageal reflux disease (GERD) after LAGB [9]. Considering the high failure rate, the damage to the lower esophageal sphincter and the alarmingly high incidence of reoperation, other bariatric procedures may be preferable in obese adolescents. In fact, the presence/absence of GERD and of T2DM guided us in selecting bypass or sleeve interventions (the latter being performed preferably in subjects who do not suffer from either condition). We try to choose a reversible procedure in youngsters. Obviously, sleeve gastrectomy is irreversible. In our opinion the adjustable band, while removable, does leave irreversible changes around the cardia, and may permanently damage the lower esophageal sphincter. This is the reason why we abandoned the adjustable band procedure in 2004 in our department. Conversely, the bypass procedure is indeed fully reversible [38].

Possible alternatives for LAGB include laparoscopic sleeve gastrectomy (LSG) and LRYGB. With the increased popularity of the LSG in the recent years, new reports have appeared investigating its use in adolescents [1,39]. The apparent ease of the procedure and the usually good reports on the outcomes have seduced a number of surgeons into performing LSG in adolescents. LSG has been used even in a 2-year-old patient suffering from extreme obesity [40]. Additionally, in a recent report by Al-Qahtani et al. [41], 108 teenagers with initial BMI of $50 \mathrm{~kg} / \mathrm{m}^{2}$, who had been followed up to 2 years, showed an average loss of $62 \%$ of excess weight with resolution of sleep apnea syndrome (20 of 22 patients) and T2DM (15 of 16 patients) and with no major postoperative complications and only $4.6 \%$ minor complications. Follow-up, however, was limited to 2 years, a time frame that is known to be advantageous in terms of weight loss outcomes after LSG [42]. Certainly, LSG is associated with drawbacks that make it less attractive for general use in adolescents. First, the procedure is irreversible. Second, there is the issue of weight regain beyond the 3 rd postoperative year. Third, we have documented that after LSG GERD requiring chronic proton pomp inhibitors (PPI) occurs in up to one third of the patients [42]. There is evidence that the chronic use of PPI may have deleterious effects on health [43].

LRYGB is probably the most popular bariatric operation. We chose this procedure for children because of its documented good long-term results and, importantly, its reversibility [44]. Opponents highlight the potential complications after LRYGB, which include micronu- 
Vilallonga et al.: Long-Term (7 Years) Follow-Up of Roux-en-Y Gastric Bypass on Obese Adolescent Patients $(<18$ Years $)$

trient deficiencies, especially iron, calcium and vitamin B12 [45, 46]. In our study, however, most of the adolescent patients showed a high compliance rate in terms of vitamin intake, and regular blood work (84\%) should contribute to lowering the incidence of deficiencies. LRYGB did not seem to jeopardize the normal growth and development of our adolescent patients.

Women with a history of bariatric surgery are at risk of micronutrient deficiencies resulting from the combination of physiologic changes related to pregnancy and iatrogenic postoperative alterations in the absorption and metabolism of crucial nutrients. Deficiencies of phylloquinone, folate, iron, calcium, zinc, magnesium, iodide, copper, and vitamins A, D and B12 in pregnant and postpartum women after bariatric surgery need to be addressed and controlled [47].

In this study, adolescent patients achieved acceptable weight loss at an average of 7 years after surgery, which is comparable to the AdG. Our outcomes are in accordance with our previously published results [48]. Interestingly, nadir weight was achieved significantly later in the ChG (after 3.7 years) compared to the AdG (2.3 years). This finding might be explained by the fact that in the ChG most individuals were still growing and in full physical development. The balance between the tendency to gain weight linked with the natural physical development on one hand and the weight loss caused by the operation on the other hand may translate into a longer weight loss process than in adults. Goldsmith et al. [49] described this previously in a non-surgical adolescent population treated by diet alone.

An important aspect when dealing with an adolescent population is the risk of undesired pregnancy. In our study, despite adequate birth control pill intake, 2 patients out of $12(17 \%)$, developed a pregnancy 6 or 8 years surgery. The use of the contraceptive pill in a non-bariatric population has a much lower failure index of $<1 \%$ [50]. The reduced activity of the pill after LRYGB may be due to altered pharmacokinetics of the drug due to the bypass anatomy [51]. Considering the abnormally high rate of unexpected pregnancy, we would suggest that the contraceptive pill should no longer be proposed as a reliable means of birth control. Hence, other methods should probably be implemented after LRYGB including spiral, mechanical means (diaphragm and condom) and hormonal slow-release preparations. Conversely, desired pregnancies did not result in problems during gestation or at birth. In fact, there is data regarding fertility, contraception and pregnancy outcomes which is limited to observational studies. Fertility is improved after bariatric surgical procedures, nutritional deficiencies for mother and child are minimal, and maternal and neonatal outcomes are acceptable with laparoscopic adjustable band and gastric bypass as long as adequate maternal nutrition and vitamin supplementation are maintained. However, special attention must be paid to adolescents in order to avoid undesired pregnancies [52, 53].

The psychological effects of a bariatric procedure cannot be overestimated when dealing with adolescents. Some studies have evaluated the impact of bariatric surgery in obese adolescents and have shown its benefit from a psychological point of view $[54,55]$. In terms of satisfaction with the procedure, there were no differences between the $\mathrm{ChG}$ and the AdG, which indicates that even after becoming adults, ex obese patients do not recall the procedure as traumatic despite what some have feared $[56,57]$. Consequently, our data seem to confirm the results published by Messiah at al. [36] who showed improvements in physical functioning, general health, self-esteem and family activities in adolescents after bariatric surgery.

\section{Conclusion}

The alarmingly increasing rate of childhood and adolescent obesity in most countries must urgently be addressed. Surgical treatment includes many modalities such as LAGB or LSG but aspects such as reversibility or long-term failure and new onset of GERD must be 
Vilallonga et al.: Long-Term (7 Years) Follow-Up of Roux-en-Y Gastric Bypass on Obese Adolescent Patients ( $<18$ Years)

considered. In our experience, LRYGB, a reversible procedure, appears to be an effective and well-accepted treatment mode for adolescent patients. Special attention must be paid to the use of birth control pills to avoid undesired pregnancy.

\section{Disclosure Statement}

Dr. Ramon Vilallonga and Dr. Simon Van de Vrande Simon have no conflicts of interest. Dr. Jacques Himpens is a consultant for Ethicon Endosurgery and Gore, but no relation to the work. The manuscript has been read and approved by all authors. No financial support for the manuscript preparation.

\section{References}

-1 Boza C, Viscido G, Salinas J, Crovari F, Funke R, Perez G: Laparoscopic sleeve gastrectomy in obese adolescents: results in 51 patients. Surg Obes Relat Dis 2012;8:133-137; discussion 137-139.

-2 Singh GK: Changes in State-Specific Childhood Obesity and Overweight Prevalence in the United States From 2003 to 2007. Arch Pediatr Adolesc Med 2010;164:598-607.

3 U.S. Centers for Disease Control and Prevention: Childhood Obesity Facts. www.cdc.gov/healthyschools/ obesity/facts.htm (last accessed March 17, 2016).

-4 Carrascosa A, Fernández JM, Fernández C, Ferrández A, López-Siguero JP,Sánchez E, Sobradillo B, Yeste D: Spanish growth studies 2008. New anthropometric standards. Endocrinol Nutr 2008;55:484-506.

-5 Krebs NF, Himes JH, Jacobson D, Nicklas TA, Guilday P, Styne D: Assessment of child and adolescent overweight and obesity. Pediatrics 2007;120(suppl 4):S193-S228.

6 National Center for Chronic Disease Prevention and Health Promotion: Obesity - Halting the Epidemic by Making Health Easier. At a Glance 2009. www.cdc.gov/nccdphp/publications/AAG/pdf/obesity.pdf (last accessed March 17, 2016).

7 Franks PW, Hanson RL, Knowler WC, Sievers ML, Bennett PH, Looker HC: Childhood obesity, other cardiovascular risk factors, and premature death. N Engl J Med 2010;362:485-493.

8 Dhir S, Ryan F: Measurement, causes and management of overweight and obesity in children. Community Pract 2010;83:32-34.

-9 Vilallonga R, Yeste D, Lecube A, Fort JM: Bariatric surgery in adolescents. Cir Esp 2012;90:619-625.

-10 Ratcliff MB, Reiter-Purtill J, Inge TH, Zeller MH: Changes in depressive symptoms among adolescent bariatric candidates from preoperative psychological evaluation to immediately before surgery. Surg Obes Relat Dis 2011;7:50-54.

-11 Skinner AC, Steiner MJ, Henderson FW, Perrin EM: Multiple markers of inflammation and weight status: crosssectional analyses throughout childhood. Pediatrics 2010;125:e801-809.

12 Inge TH: Baseline BMI is a strong predictor of nadir BMI after adolescent gastric bypass. J Pediatr 2010;156: 103-108.

13 Koebnick C, Smith N, Coleman KJ, Getahun D, Reynolds K, Quinn VP, Porter AH, Der-Sarkissian JK, Jacobsen SJ: Prevalence of extreme obesity in a multiethnic cohort of children and adolescents. J Pediatr 2010;157:26-31. e2.

14 Christou NV, Sampalis JS, Liberman M, Look D, Auger S, McLean AP, MacLean LD: Surgery decreases long-term mortality, morbidity, and health care use in morbidly obese patients. Ann Surg 2004;240:416-423; discussion 423-424.

15 Yitzhak A, Mizrahi S, Avinoach E: Laparoscopic gastric banding in adolescents. Obes Surg 2006;16:1318-1322.

16 Inge TH, Xanthakos S: Sleeve gastrectomy for childhood morbid obesity: why not? Obes Surg 2010;20:118 120.

-17 Lawson ML, Kirk S, Mitchell T Chen MK, Loux TJ, Daniels SR, Harmon CM, Clements RH, Garcia VF, Inge TH; Pediatric Bariatric Study Group: One-year outcomes of Roux-en-Y gastric bypass for morbidly obese adolescents: a multicenter study from the Pediatric Bariatric Study Group. J Pediatr Surg 2006;41:137-143; discussion 137-143.

18 Daniels SR, Arnett DK, Eckel RH, et al: Overweight in children and adolescents: pathophysiology, consequences, prevention, and treatment. Circulation 2005;111:1999-2012.

19 Ibele AR, Mattar SG: Adolescent bariatric surgery. Surg Clin North Am 2011;91:1339-1351.

20 Sinha A, Kling S: A review of adolescent obesity: prevalence, etiology, and treatment. Obes Surg 2009;19: 113-120.

21 Woolford SJ, Clark SJ, Gebremariam A, Davis MM, Freed GL: To cut or not to cut: physicians' perspectives on referring adolescents for bariatric surgery. Obes Surg 2010;20:937-942.

22 Iqbal CW, Kumar S, Iqbal AD, Ishitani MB: Perspectives on pediatric bariatric surgery: identifying barriers to referral. Surg Obes Relat Dis 2009;5:88-93. 
Vilallonga et al.: Long-Term (7 Years) Follow-Up of Roux-en-Y Gastric Bypass on Obese Adolescent Patients (<18 Years)

23 Papadia FS, Adami GF, Marinari GM, Camerini G, Scopinaro N: Bariatric surgery in adolescents: a long-term follow-up study. Surg Obes Relat Dis 2007;3:465-468.

24 Buchwald H, Avidor Y, Braunwald E, Jensen MD, Pories W, Fahrbach K, Schoelles K: Bariatric surgery: a systematic review and meta-analysis. JAMA 2004;13;292:1724-1737.

25 Aikenhead A, Lobstein T, Knai C: Review of current guidelines on adolescent bariatric surgery. Clin Obes 2011; 1:3-11.

-26 O’Brien PE, Sawyer SM, Laurie C, Brown WA, Skinner S, Veit F, Paul E, Burton PR, McGrice M, Anderson M, Dixon JB: Laparoscopic adjustable gastric banding in severely obese adolescents: a randomized trial. JAMA 2010;303:519-526.

27 DeMaria EJ, Pate V, Warthen M, Winegar DA: Baseline data from American Society for Metabolic and Bariatric Surgery-designated bariatric Surgery Centers of Excellence using the bariatric outcomes longitudinal database. Surg Obes Relat Dis 2012;6:347-355.

28 Dolan L, Creighton G, Hopkins, Fielding G: Laparoscopic gastric banding in morbidly obese adolescents Obes Surg 2003;13:101-104.

29 Fielding GA, Duncombe JE: Laparoscopic adjustable gastric banding in severely obese adolescents Surg Obes Relat Dis 2005;1:399-405.

-30 Silberhumer GR, Miller K, Kriwanek S, Widhalm K, Pump A, Prager G: Laparoscopic adjustable gastric banding in adolescents: the Austrian experience. Obes Surg 2006;16:1062-1067.

-31 Angrisani L, Favretti F, Furbetta F, Paganelli M, Basso N, Doldi SB, Iuppa A, Lucchese M, Lattuada E, Lesti G, Capizzi FD, Giardiello C, Di Lorenzo N, Veneziani A, Alkilani M, Puglisi F, Gardinazzi A, Cascardo A, Borrelli V, Lorenzo M: Obese teenagers treated by Lap-Band System: the Italian experience. Surgery 2005;138:877-881.

-32 Horgan S, Holterman MJ, Jacobsen GR, Browne AF, Berger RA, Moser F, Holterman AX: Laparoscopic adjustable gastric banding for the treatment of adolescent morbid obesity in the United States: a safe alternative to gastric bypass. J Pediatr Surg 2005;40:86-90; discussion 90-91.

-33 Nadler EP, Youn HA, Ginsburg HB, Ren CJ, Fielding GA: Short-term results in 53 US obese pediatric patients treated with laparoscopic adjustable gastric banding. J Pediatr Surg 2007;42:137-141; discussion 141-142.

-34 Jen HC, Rickard DG, Shew SB, Maggard MA, Slusser WM, Dutson EP, DeUgarte DA: Trends and outcomes of adolescent bariatric surgery in California, 2005-2007. Pediatrics 2010;126:e746-753.

-35 Nadler EP, Brotman LM, Miyoshi T, Fryer GE Jr, Weitzman M: Morbidity in obese adolescents who meet the adult National Institutes of Health criteria for bariatric surgery. J Pediatr Surg 2009;44:1869-1876.

-36 Messiah SE, Lopez-Mitnik G, Winegar D, Sherif B, Arheart KL, Reichard KW, Michalsky MP, Lipshultz SE, Miller TL, Livingstone AS, de la Cruz-Muñoz N: Changes in weight and co-morbidities among adolescents undergoing bariatric surgery: 1-year results from the Bariatric Outcomes Longitudinal Database. Surg Obes Relat Dis 2013;9:503-513.

37 Himpens J, Cadière GB, Bazi M, Vouche M, Cadière B, Dapri G: Long-term outcomes of laparoscopic adjustable gastric banding. Arch Surg 2011;146:802-807.

-38 Azagury DE, Varban O, Tavakkolizadeh A, Robinson MK, Vernon AH, Lautz DB: Does laparoscopic gastric banding create hiatal hernias? Surg Obes Relat Dis 2013;9:48-52.

-39 Vilallonga R, van de Vrande S, Himpens J: Laparoscopic reversal of Roux-en-Y gastric bypass into normal anatomy with or without sleeve gastrectomy. Surg Endosc. 2013 Dec;27(12):4640-8.

40 Mohaidly M: Laparoscopic sleeve gastrectomy in a two ( 2 ) years old child. 1st Congress for International Metabolic and Bariatric Surgery (SASMBS), 2013.

41 Alqahtani AR, Antonisamy B, Alamri H, Elahmedi M, Zimmerman VA: Laparoscopic sleeve gastrectomy in 108 obese children and adolescents aged 5 to 21 years. Ann Surg 2012;256:266-73.

42 Himpens J, Dobbeleir J, Peeters G: Long-term results of laparoscopic sleeve gastrectomy for obesity. Ann Surg 2010;252:319-324.

43 Vakil N: Prescribing proton pump inhibitors: is it time to pause and rethink? Drugs 2012;72:437-445.

44 Buchwald H, Oien DM: Metabolic/bariatric surgery worldwide 2011. Obes Surg 2013;23:427-436.

45 Strauss RS, Bradley LJ, Brolin RE: Gastric bypass surgery in adolescents with morbid obesity. J Pediatr 2001; 138:499-504.

46 Maggard MA, Shugarman LR, Suttorp M, Maglione M, Sugerman HJ, Livingston EH, Nguyen NT, Li Z, Mojica WA, Hilton L, Rhodes S, Morton SC, Shekelle PG: Meta-analysis: surgical treatment of obesity. Ann Intern Med 2005; 142:547-559.

47 Machado SN, Pereira S, Saboya C, Saunders C, Ramalho A: Influence of Roux-en-Y gastric bypass on the nutritional status of vitamin A in pregnant women: a comparative study. Obes Surg 2016;26:26-31.

48 Himpens J, Verbrugghe A, Cadière GB, Everaerts W, Greve JW: Long-term results of laparoscopic Roux-en-Y Gastric bypass: evaluation after 9 years. Obes Surg 2012;22:1586-1593.

49 52. Goldschmidt AB, Wilfley DE, Paluch RA, Roemmich JN, Epstein LH: Indicated prevention of adult obesity: how much weight change is necessary for normalization of weight status in children? JAMA Pediatr 2013;167: 21-26.

50 Bitzer J: Oral contraceptives in adolescent women. Best Pract Res Clin Endocrinol Metab 2013;27:77-89.

51 Maggard MA, Yermilov I, Li Z, Maglione M, Newberry S, Suttorp M, Hilton L, Santry HP, Morton JM, Livingston EH, Shekelle PG: Pregnancy and fertility following bariatric surgery: a systematic review. JAMA 2008;300: 2286-2296. 
52 Shekelle PG, Newberry S, Maglione M, Li Z, Yermilov I, Hilton L, Suttorp M, Maggard M, Carter J, Tringale C, Chen S: Bariatric surgery in women of reproductive age: special concerns for pregnancy. Evid Rep Technol Assess (Full Rep). 2008;169:1-51.

-53 Jans G, Matthys C, Bogaerts A, Lannoo M, Verhaeghe J, Van der Schueren B,Devlieger R: Maternal micronutrient deficiencies and related adverse neonatal outcomes after bariatric surgery: a systematic review. Adv Nutr. 2015;6:420-429.

54 Sysko R, Devlin MJ, Hildebrandt TB, Brewer SK, Zitsman JL, Walsh BT: Psychological outcomes and predictors of initial weight loss outcomes among severely obese adolescents receiving laparoscopic adjustable gastric banding. J Clin Psychiatry 2012;73:1351-1357.

55 Järvholm K, Olbers T, Marcus C, Mårild S, Gronowitz E, Friberg P, Johnsson P, Flodmark CE: Short-term psychological outcomes in severely obese adolescents after bariatric surgery. Obesity (Silver Spring) 2012;20:318323.

56 Barnett SJ, Stanley C, Hanlon M, et al: Long-term follow-up and the role of surgery in adolescents with morbid obesity. Surg Obes Relat Dis 2005;1:394-398.

57 Kirschenbaum DS, Gierut K: Treatment of childhood and adolescent obesity: an integrative review of recent recommendations from five expert groups. J Consult Clin Psychol 2013;81:347-360. 